\title{
DERRAMAM-SE OS HORIZONTES: POR UMA EXPERIÊNCIA LITERÁRIA CINÉTICA
}

Ligia G. Diniz

Universidade de Brasilia

Brasilia, DF, BR.

\section{Resumo}

Neste ensaio, proponho pensar em possibilidades de leitura de obras literária que não se restrinjam à tradição hermenêutica e abram espaço para uma vivência afetiva da literatura, isto é, para seus efeitos sensoriais, perceptuais e emocionais. Para tanto, entendo que reflexões fundamentadas no comportamento e nas possibilidades de consciência animal possam ser um ponto de partida para se pensar a configuração de um espaço híbrido na consciência, em um imaginário somático e cinético que alargue a definição e os horizontes da representação literária.

Palavras-chave: pós-humanismo, etologia, imaginação, experiência literária, afeto

\section{THE HORIZONS COME: IN DEFENSE OF KINETIC LITERARY EXPERIENCES}

\begin{abstract}
In this essay, I aim to reflect upon possibilities of literary experiences that are not restricted to the hermeneutic tradition and thus provide space for an affective take on literature, namely through sensorial, perceptual and emotional effects. With that in mind, I propose that poetic elucubrations based on animal consciousness could be a starting point in the configuration of a hybrid conscious state, in a somatic and kinetic imaginary, which then might broaden both the notion and the horizons of literary representation.
\end{abstract}

Keywords: post-humanism, ethology, imagination, literary experience, affect

Refletir sobre a experiência de leitura literária e sobre a noção de representação na literatura significa, tradicionalmente, pensar sobre a construção de sentidos por meio de uma linguagem organizada de maneira singular. A possibilidade de retratar, questionar ou ressignificar o mundo real, tanto quanto os limites desse escopo, vem, assim, ligada à constituição de significados a partir do texto apresentado e experimentado: expõe-se um mundo ficcional ou poético para, de algum modo, tocar a realidade, ou indicar a intangibilidade, pela palavra, do mundo material. Em qualquer caso, entende-se que a consciência, na leitura, está posta em movimento para erigir ou desvendar sentidos e, por meio deles - caso se acredite no poder representacional do texto literário -, acessar o mundo à nossa volta. $\mathrm{O}$ que defendo neste ensaio é uma outra forma de conceber a representação literária da realidade e, para aí chegar, uma outra forma de encarar nossas próprias possibilidades de experiências conscientes. No cerne dessa defesa está a proposta de uma concepção de consciência que não a torne sinônimo de autoconsciência, isto é, uma concepção de consciência que não a torne equivalente à interpretação e entendimento. Para tanto, volto o olhar e a imaginação para a consciência dos animais.

Se admitimos que cabe às ciências - notadamente, à etologia - uma investigação objetiva sobre a mente, as emoções e a sensações das outras espécies, nenhuma outra área de conhecimento, que não a literatura, pare-

\footnotetext{
“Doutora em Literatura pela Universidade de Brasília (UnB, 2016), com período "sanduíche" na Universidade de Stanford (EUA, 2014-2015). Mestra em
} Literatura, também pela UnB (2012). Seu endereço de e-mail é ligiadiniz@gmail.com. 
ce-me ser mais adequada, por sua vocação ao exercício da alteridade, a aceitar o desafio de conceber as possibilidades de experiência desse outro absoluto. Mais interessante do que isso, no entanto, é perceber como o exercício de imaginação sobre a consciência animal nos leva a vislumbrar a potencialidade, e também as barreiras, da consciência humana e de suas experiências da realidade. No que diz respeito à leitura de literatura, engendrar formas não humanas de consciência e de imaginação vale como exercício fundamental para apreender a experiência viva que a linguagem nos oferece: nos colocar nos calcanhares de personagens e nos envolver na atmosfera de cenários, ritmos e melodias, cores e outras sensações.

O escritor de ficção científica Stanislaw Lem sempre lamentou que a versão cinematográfica de seu clássico de 1961, Solaris, realizada por Andrei Tarkovski houvesse sequestrado as considerações cognitivas e epistemológicas do romance, tendo se transformado em uma espécie de "versão espacial" de Crime e castigo, em vez de tratar, como era a intenção do original, da impossibilidade de comunicação entre os seres humanos e espécies extraterrestres. ${ }^{1}$ No romance, um dos cientistas tripulantes da expedição original, que orbita o estranho planeta Solaris, fala ao recém-chegado psicólogo Kelvin - que acaba de ver, materializada, a ex-mulher, que se suicidara alguns anos antes - sobre este e outros estranhos fenômenos que vêm acontecendo na estação: "Alguns eventos que de fato aconteceram são terríveis, mas o que é mais horrível ainda é aquilo que não aconteceu, o que nunca existiu. [...] Há muitas coisas, situações, que ninguém ousou externar, mas que a mente produziu por acidente em um momento de aberração, ou de loucura, como você quiser chamar. No estágio seguinte, a ideia se torna carne e osso" (LEM, 1970, p. 71). ${ }^{2}$ Diante de um Kelvin estarrecido, Snaut continua:

Nós partimos rumo ao cosmos, prontos para qualquer coisa: solidão, dificuldades, exaustão, morte. A modéstia nos impede de dizer, mas há momentos em que pensamos muito bem de nós mesmos. Ainda assim, se examinarmos mais de perto, nosso entusiasmo não passa de fingimento. Não queremos conquistar o cos- mos, simplesmente queremos estender as fronteiras da Terra até os limites do universo. [...] Somos humanitários e nobres; não queremos escravizar outras raças, simplesmente queremos passar a eles nossos valores e apreender, em troca, sua tradição. Pensamos em nós mesmos como os Cavalheiros do Contato Sagrado. Essa é outra mentira. Estamos apenas procurando o Homem. Não precisamos de outros mundos. Precisamos de espelhos. Nós não sabemos o que fazer com outros mundos. (LEM, 1970, p. 72)

De fato, esse tipo de angústia é bem menos evidente na película, que, como o próprio Tarkovski (1998, p. 239, grifo meu) descreve, "tratava de pessoas perdidas no Cosmo e obrigadas, querendo ou não, a adquirir e dominar mais uma porção de conhecimento". Mesmo que o filme em si, em sua dicção complexa, acabe por explorar as arestas entre realidade, consciente e inconsciente, a razão ainda ocupa o centro do palco, e o inconsciente é seu antagonista: "A ânsia infinita do homem por conhecimento, que lhe foi dada gratuitamente, é uma fonte de grande tensão, pois traz consigo ansiedade constante, sofrimento, pesar e desilusão, já que a verdade última nunca pode ser conhecida" (TARKOVSKIAEI, 1998, p. 239). A mente alienígena é, portanto, vista como um objeto de conhecimento racional: ainda que se reconheça o limite da razão nesse âmbito, não se considera a possibilidade de um outro tipo de partilha consciente.

Se a consciência extraterrestre é o outro total da ficção científica, os bichos que compartilham da Terra conosco são a alteridade absoluta mais palpável com que temos contato, e, do mesmo modo que a imposição de um paradigma de racionalidade calcado no entendimento humano tem consequências devastadoras para a tripulação em Solaris, essa mesma imposição frequentemente nos impede de vislumbrar afetos e outras experiências animais e - o que mais nos interessa aqui - nos atrapalha perceber de que modo o amortecimento mais ou menos intencional desses mesmos afetos e experiências em nós mesmos reduz a riqueza da nossa vivência consciente. Nesse contexto, a experiência de arte e, entre suas variedades, a experiência literária são vítimas frequentes dessa constante subordinação da consciência à razão e aos processos interpretativos. 


\section{Literatura e imaginação empática}

Em outubro de 1997, J. M. Coetzee apresentou duas palestras na Universidade de Princeton, nos

Estados Unidos, depois reunidas no volume The Lives of Animals (As vidas dos animais), em que a dificuldade humana de admitir a possibilidade de outras formas de consciência, assim como de lidar com a própria mente, é tomada por outra perspectiva. Diferentemente dos demais intelectuais convidados a falar nas prestigiosas Tanner Lectures, o escritor sul-africano escolheu ficcionalizar as palestras, criando a personagem conferencista Elizabeth Costello, também escritora consagrada, e evitando assim evocar sua própria autoridade, para demandar do público uma tentativa de repensar nossas relações com as outras espécies.

$\mathrm{Na}$ primeira fala, "The philosophers and the animals" ("Os filósofos e os animais"), Costello questiona a naturalidade com que assumimos e lidamos com determinados conceitos e seus valores, como o de razão, que parece a ela, de modo suspeito, coincidir com o próprio pensamento humano e, mais especificamente, com a tradição racionalista ocidental. Partindo do princípio de que essa racionalidade é apenas um dos modos de se abordar a natureza e a realidade, e de com ela se relacionar, Costello propõe um exercício de recusa do que entende como "uma vasta tautologia", isto é, a convencional defesa da razão, como única forma de acessar o mundo, posta em prática pela própria razão (COETZEE, 1999, p. 23, 25).

Coetzee, isto é, Costello faz referência ao muito citado artigo de Thomas Nagel, no qual este afirma que ter experiências conscientes pressupõe haver "algo que é como ser aquele organismo"3 (NAGEL, 1974, p. 436, grifo no original). $\mathrm{O}$ artigo, intitulado "What is it like to be a bat?" ("Como é ser um morcego?"), recusa, precisamente, a possibilidade de um ser humano responder à pergunta que enuncia no título: "Nossa experiência própria provê o material básico para a nossa imaginação, cujo alcance é, portanto, limitado", escreve Nagel (1974, p. 439). Não adianta, diz ele, tentarmos imaginar que temos uma membrana ligando os braços ao tronco ou que voamos, tampouco que dormimos pendurados de cabeça para baixo, ingerimos insetos ou que, por causa de nossa visão deficiente, reconhecemos o mundo por meio de um sistema de reverberação de sinais sonoros. Ele escreve, então, que, mesmo que pudéssemos imaginar tudo isso, só conheceríamos, ou emularíamos, o comportamento do morcego, sem chegar perto de tanger sua consciência ou suas sensações. Se o objetivo for saber como é, para um morcego, ser um morcego, depararíamos com uma quimera que morre na praia, já que, para Nagel, a nossa imaginação, entendida como um recurso de nossa própria mente, não está apta a tal tarefa.

Elizabeth Costello discorda. Para ela, Nagel, apesar de seu humor e capacidade de argumentação racional, oferece uma resposta "tragicamente limitada" (COETZEE, 1999, p. 31). Se o objetivo do filósofo, ao evocar um morcego, é o de aludir a uma existência completamente estranha à nossa, ela propõe então uma existência ainda mais alheia: a de um corpo morto. E, mesmo que ninguém possa, de fato, conceber o que é ser um cadáver, a autora, já idosa, defende que é possível, por um esforço de imaginação, por alguns breves instantes, saber, na própria pele, como é sê-lo. Esse conhecimento, diz ela, não é abstrato - no estilo "eu sei que eu sou um ser humano e que vou morrer" -, e sim corpóreo (embodied): "Por um momento, nós somos esse conhecimento", ela resume. Mas, questiona-se ela, nos termos de Nagel, o que quer dizer esse conhecimento corpóreo de que vou morrer; isto é, sei como um cadáver se sente ou sei como eu me sentiria sendo apenas um corpo morto? Ela reconhece então o limite da imaginação corpórea no que diz respeito à experiência de algo sem vida: "O que eu sei é o que um cadáver não pode saber: que ele está extinto, que não sabe nada e nunca mais vai saber nada". Essa outra forma de consciência não pode durar muito, o que não quer dizer que seja sem importância, pelo contrário: "Por um instante, antes que toda a minha estrutura de conhecimento desmorone em pânico, estou viva dentro dessa contradição, viva e morta ao mesmo tempo" (COETZEE, 1999, p. 32).

A experiência de se imaginar um morcego, isto é, de buscar saber como é ser um morcego, é algo completamente oposto. No entendimento de Costello, ser plenamente um morcego não é, como propõe Nagel, possível apenas se experimentarmos a vida por meio das 
modalidades sensoriais de um morcego. Para a autora, a imaginação empática é algo mais essencial e toca precisamente o impacto da realidade sobre as sensações, não importando a modalidade destas: "Ser um morcego vivo é estar cheio de ser. Ser plenamente um morcego é como ser plenamente humano, que é também estar cheio de ser", e cada uma das modalidades seria apenas uma consideração secundária. "Estar cheio de ser [full of being] é viver como corpo-alma. Um nome para a experiência de ser plenamente é alegria" (COETZEE, 1999, p. 32-33, grifo no original).

A partir daí, a escritora delineia um outro modo de consciência oposto à linhagem racionalista de Descartes e ao abandono cartesiano do corpo à posição de mecanismo: "Ao pensar, à reflexão, eu oponho a plenitude, a corporalidade, a sensação de ser [...], a sensação - uma sensação gravemente afetiva - de ser um corpo com membros que têm extensão no espaço, de estar vivo no mundo". Nesse modo de consciência, ela propõe, não há limites para alcançarmos, por meio da imaginação empática, outras formas de experiência viva e de consciência (COETZEE, 1999, p. 35).

Essa liberdade, ou essa capacidade, está no coração da literatura. A aula seguinte de Elizabeth Costello chama-se, justamente, "The poets and the animals" ("Os poetas e os animais"). O centro de irradiação da apresentação é o poema "The jaguar", de Ted Hughes. O bicho jaguar é, por sua vez, o centro de irradiação do poema: Hughes constrói como cenário um zoológico, no qual a multidão está enlevada pelo espetáculo de um jaguar em sua cela, e, entre os espectadores, o poeta, "em transe e horrorizado e estupefato", procura transformar em linguagem algo que está além de sua capacidade de entendimento (COETZEE, 1999, p. 50-51). Precisamos ler o poema:

The apes yawn and adore their fleas in the sun. The parrots shriek as if they were on fire, or strut Like cheap tarts to attract the stroller with the nut. Fatigued with indolence, tiger and lion

Lie still as the sun. The boa-constrictor's coil Is a fossil. Cage after cage seems empty, or Stinks of sleepers from the breathing straw. It might be painted on a nursery wall.
But who runs like the rest past these arrives At a cage where the crowd stands, stares, /mesmerized,

As a child at a dream, at a jaguar hurrying enraged Through prison darkness after the drills of his eyes

On a short fierce fuse. Not in boredom The eye satisfied to be blind in fire, By the bang of blood in the brain deaf the ear He spins from the bars, but there's no cage to him

More than to the visionary his cell: His stride is wildernesses of freedom: The world rolls under the long thrust of his heel. Over the cage floor the horizons come.

(HUGHES, 2010a, p. 16)

Os olhos do jaguar, como brocas, "pungem pelo breu da prisão", como diz a bela tradução de Sérgio Alcides (HUGHES, 2010b, p. 40), pois "para ele não há jaula/ Mais do que para o visionário existe sua cela". Costello faz notar aos estudantes: "A jaula não tem realidade para ele; ele está em outro lugar [...] porque sua consciência é cinética e não abstrata: o ímpeto de seus músculos o move através de um [...] espaço circular que gira sobre si mesmo" (COETZEE, 1999, p. 51). "O poema", diz a conferencista, "nos pede para nos imaginarmos naquele modo de se mover, para que habitemos aquele corpo": não é uma questão de entender como funciona a mente de outro ser, mas de compartilhar sua existência física no mundo.

\section{Confrontos com o outro absoluto}

Partimos, assim, da ideia de que o animal é o outro total, na medida em que guarda uma forma de consciência que podemos apenas tangenciar, sem jamais ou ainda - conceber, factualmente, como o mundo se lhe apresenta. Como bem escreve Maria Esther Maciel (2016, p. 13), os animais são objeto de afeição e temor, são subjugados, admirados, confinados e mesmo humanizados, mas, paradoxalmente, resistem a se deixar capturar em sua "alteridade radical". Mick Smith, em um ensaio tão instigante quanto comovente acerca dos atropelamentos de animais selvagens e domésticos em estradas na América do Norte, reflete sobre como esses incidentes expõem indícios brutais do nosso alheamen- 
to quanto aos outros animais, e sobre como esse alheamento é posto em xeque nesses momentos fatais.

A própria dificuldade em tratar tais eventos com a gravidade que lhes é inerente aponta, na opinião de Smith, o quanto a fragilidade do outro-animal nos impacta para além de um simples transtorno em nossos trajetos cotidianos. Mais do que isso, escreve o autor, nesses incidentes, nosso alheamento é amplificado pela participação do automóvel, que nos encapsula e nos "protege" do mundo natural, isto é, do potencial de impacto afetivo que o mundo natural guarda para nós. Esse impacto é, ainda assim, evidenciado em tais momentos fugazes em que ao outro-animal é "permitido compartilhar tão pouco do 'nosso' mundo" (SMITH, 2009, p. 21) - um mundo que, ali, nos joga menos para o lado do orgânico e mais para o lado da máquina, com a qual formamos um "organismo cibernético" com potencial extremo para a destruição.

Para o autor, com efeito, são sintomáticas as reações como o humor, o cinismo ou a explicação recheada de hipocrisia exemplificada pelo comentário: "Mas aquele bicho apareceu do nada...."

Smith questiona se é um fracasso da nossa capacidade de empatia, ou talvez uma forma de negação e de autoproteção, o que faz com que a nossa imaginação seja confrontada com uma espécie de limite duplo: de um lado uma insuficiência de nossa capacidade de "entendimento hermenêutico" acerca desse confronto, e de outro uma barreira que nos impede de expressar publicamente a narrativa do impacto da vivência de uma morte inesperada. Em qualquer caso, o que está em discussão é o limite (assim como a produtividade) da antropomorfização como forma de se relacionar de modo ético, mas também fenomenológico e afetivo, com o animal. Será, questiona Smith (2009, p. 24), que somos de fato incapazes de compartilhar esse espaço de dor, ou será que o desprezo casual, a ironia, até mesmo a irritação diante do estorvo no tráfico, podem manifestar, na realidade, um reconhecimento subliminar do absurdo fundamental de situações partilhadas pelos humanos e os outros animais?

Smith recorre a Heidegger para refletir sobre as diferentes relações que humanos e outros animais estabelecem com o mundo. Vale a pena retomar o pen- samento do filósofo alemão. Em seu curso na Universidade de Freiburg mais tarde reunido na obra Conceitos Fundamentais da Metafísica, Heidegger citava o poeta conterrâneo Novalis para propor que o Stimmung - a disposição, o tom - fundamental da filosofia seria um sentimento de saudade de casa (Heimweh), "uma ânsia por se sentir em casa em todos os lugares" (NOVALIS apud HEIDEGGER, 1995, p. 5). Essa ânsia teria como objeto um desejo de estar inteiramente no mundo - um desejo cuja plena realização é, por princípio, impossível, na medida em que temos consciência de nossa finitude, mas que, justamente por essa consciência, nos move adiante, em direção a uma tal conexão cosmológica.

Em Heidegger, fica evidente como a "saudade de casa" é a falta que move o filosofar: seu gatilho, e não sua realização. Aqui, a filosofia é precisamente a busca por um pensamento que permita se delinear um estado em que o mundo das coisas se ofereça imediatamente acessível. "Mundo [...] significa propriamente acesso aos entes como tais. Mas esse acesso tem como base a manifestabilidade dos entes como tais, [...] e em sua totalidade" (HEIDEGGER, 1995, p. 284) - ou seja, os entes (como um todo) devem se fazer acessíveis como tais, isto é, em respeito ao seu caráter de seres: devem se mostrar como entes que são. Nesse contexto, o homem seria, diferentemente dos outros animais, "formador" de mundo: enquanto os bichos são "pobres em mundo", cabendo a eles o que Heidegger chama de estado de captividade (Benommenheit) - isto é, estando expostos às coisas do mundo sem que possam apreendê-las enquanto tais -, aos seres humanos essa exposição é, contraditoriamente, limitada pela capacidade de acessá-las como aquilo que são, tornando-as, e ao mundo, objetos a uma certa distância de nós.

Mick Smith (2009, p. 29) vai ao ponto quando afirma que essa "pobreza de mundo" que Heidegger identifica nos animais - isto é, o fato de estes não terem consciência do mundo como tal, e de sua existência finita dentro desse mundo - significa, ao mesmo tempo, que eles têm, em outros sentidos, uma vida "incompreensivelmente rica". É o próprio Heidegger (1995, p. 255) quem o reconhece, ao afirmar que, para os bichos, a vida é um domínio cujo potencial de abertura (para as coisas do mundo) é maior do que o de qualquer 
experiência humana. Os termos fundamentais para a experiência viva do mundo pelo animais, como indica Smith, são "envolvimento" e "imersão". O ponto em que tanto Smith quanto este ensaio se afastam do pensamento heideggeriano é aquele que tange a distância entre a experiência humana e a animal - para o alemão, ela é intransponível; para nós, essa concepção não passa de um equívoco do antropomorfismo convencional, segundo o qual interpretamos as experiências vivas dos animais a partir de nossos próprios critérios. Em outras palavras, não é porque não temos como acessar a consciência animal que não podemos de algum modo compartilhar suas experiências - mesmo porque, em última análise, não podemos acessar as consciências de nossos amigos, amantes, parentes, e ainda assim compartilhamos afetivamente suas vivências.

"Afetivamente" é o qualificador fundamental desse compartilhamento de mundo de que somos capazes. Como escreve Smith (2009, p. 29), apesar da dificuldade em colocar em palavras o que o animal sente, ou de efetivamente "adentrar o 'mundo' do animal", as emoções são aquilo que oferece uma possibilidade de transpor a distância entre nós. O problema central - e questão capital quando o intuito é pensar modos de experimentar a literatura de modo não hermenêutico - é precisamente como conciliar emoção e palavra; afeto e logos.

Nas seções - ou aulas - finais dos Conceitos Fundamentais, Heidegger mostra-se, justamente, insatisfeito com a ideia de mundo como suficiente para compor a relação que deseja observar entre o homem (ou, mais precisamente, Dasein) e os demais seres e coisas. A partir de uma reflexão sobre a base das condições de possibilidade de discurso (logos) - que não se reduziriam apenas à característica de formação de mundo atribuída ao homem, mas remeteriam a algo anterior -, Heidegger pensa a origem do discurso como um todo, um conjunto indissociável e agregador. Pensado como uma habilidade, o logos carregaria em si, como condição de existência, a possibilidade de uma relação com os demais entes como tais - isto é, ainda não mediada pelo próprio logos - estar à disposição do homem (HEIDEGGER, 1995, p. 337). Para Heidegger, portanto, o discurso não cria a relação com os seres enquanto tais
- nem mesmo a manifestabilidade desses seres enquanto tais: o discurso, de fato, só é possível por causa dessa relação e dessa manifestabilidade. Em contrapartida, o discurso revela a verdade apenas na dimensão da diferenciação, do "isto ou aquilo", mas não como verdade - como desvelamento - dos seres (HEIDEGGER, 1995, p. 340). O logos só pode apontar um ente se o ente antes de tudo se manifestar como ente. Aqui já estaria, talvez, implícita a ideia, desenvolvida mais adiante (ver HEIDEGGER, 2013), de que o logos, ao apontar, também encerra o espaço de desvelamento desse ente como tal.

\section{Palavra e imaginação}

A tensão entre palavra e mundo é fundamental neste ensaio. O espaço de compartilhamento de uma consciência não racional - a razão entendida sob a perspectiva humana ocidental moderna - engendrado por momentos do nosso confronto com o outro absoluto, isto é, o animal não humano, aparece aqui como um impulso a disparar formas de encarar nossas próprias possibilidades conscientes. Mick Smith foca a ideia de "emoções" como a dimensão que temos em comum com os bichos. Prefiro falar em afetos, entendidos como as comoções somáticas - sensações físicas e emoções -, que ocupam a periferia da atenção consciente ou tomam todo o espaço consciente quando a dimensão do entendimento racional está enfraquecida. No caso da experiência literária, o afeto se traduziria, assim, como o impacto do outro literário sobre nossa consciência, e nosso corpo, antes que se converta em sentido; mais do que isso, um impacto que carrega dentro de si um elemento primordial, feito apenas de qualidades não preenchidas, e que é pura possibilidade, mas nem por isso menos real: o susto do sabor da madalena proustiana, que não pode durar mais de um centésimo de segundo antes de se converter em desejo de entender. Como possibilidade e impacto, os afetos são, de fato, as forças em ação nas representações literárias e resistem à significação e à mediação, por sua intensidade não reduzível à significação (ver, sobre isso, ABEL, 2007). Motores de comoção no indivíduo, os afetos ou resistem à circunscrição da vida em entendimento, ou escapam até mesmo à configuração da experiência viva 
- a experiência consciente enquanto em curso, antes de qualquer configuração reflexiva -, constituindo uma potência em si própria.

A experiência dos afetos guarda, portanto, um paradoxo essencial, que tem sua origem na centralidade da autoconsciência - da consciência que reflete sobre si própria - para o ser humano. Uma emoção ou sensação intensas têm qualidade e energia intrínsecas a elas. Para então apreendermos essa energia, as reduzimos a ecos reflexivos, o que engendra a nostalgia e um desejo de viver novas emoções e sensações. Isso não quer dizer que consciência e pensamento reflexivo se equivalem, o que faria com que sensações e emoções ficassem fora do radar consciente, ou que estas só existissem quando refletimos sobre elas (ou sem que necessariamente se tornem objeto de reflexão). Ao contrário, só podemos refletir sobre elas - podemos, não necessariamente o $f a$ zemos - porque elas emergem à consciência, ainda que às vezes de forma volátil. Mas, nessa transmutação, os afetos se desvanecem, tornando-se como que a nostalgia de si mesmos, ou, pelo menos, perdem sua intensidade, resistindo apenas como formas evaporadas. É precisamente o que se perde nessa conversão o que nos interessa aqui, por seu potencial de nos trazer para casa, ainda que por momentos brevíssimos. E é nesse sentido que pensar formas de consciência animal pode nos ajudar a refletir sobre espaços da nossa própria consciência que pouco acessamos deliberadamente, sobretudo quando o assunto é uma atividade primordialmente intelectual como a leitura literária.

A poeta norte-americana Vicki Hearne, que atuou durante décadas como treinadora de cães e de cavalos, produziu uma obra vigorosa calcada na alteridade dos animais, vivenciada na linguagem como algo ao mesmo tempo íntimo e aterrador. No centro de muitos de seus poemas, não à toa, sobressaem, de um lado, a vocação do humano para o nomear das coisas, e, de outro, os movimentos animais como forma básica de estar no mundo, e de resistir ao poder na nomeação. Em seus textos teóricos, Hearne insiste na relação entre consciência e linguagem, humana ou animal, mas na poesia o movimento se contrapõe, em formas como as de dança, olhar e luz, em que consciência equivale a afeto, não a significação.

De qualquer modo, em ambos os gêneros produzi- dos por Hearne, a ideia de antropomorfização se equilibra entre o absurdo de impor padrões de racionalidade humana aos animais e a rejeição contumaz da ciência moderna em conceber a possibilidade de os animais compartilharem conosco certas inclinações, afetivas, de relação com o mundo - inclinações que aqueles que convivem com animais intuem verdadeiras ou, ao menos, prováveis, como alguma forma de afeição, ou de amor, respeito etc. Hearne (2007a, p. 6-8) cita o exemplo do cãozinho que se esconde do tutor após fazer algo proibido, e o do polvo que se abriga atrás de uma parede de vidro, em um aquário-laboratório, porque aquele (não-)esconderijo era o único, ali, possível, e porque a relação de temor, e as reações subsequentes, não deve cumprir todos os pressupostos humanos - como a primazia da visão - para que tenha interseções com o comportamento afetivo humano. Mais do que isso: para que a percepção de si próprio como um indivíduo (self) seja uma possibilidade aceita por nós.

$\mathrm{Na}$ medida em que os ensaios de Hearne partem, explicitamente, da visão da treinadora, a criação de um espaço de linguagem compartilhado por humano e animal é a preocupação principal (HEARNE, 2007a, p. 20), e o esmero ali é em defender a noção de que a consciência animal é produtora de linguagem (e não só de sinais instintivos). Mais: que esta guarda uma potencialidade compatível com o "tamanho e o tipo de espaço social" por ela criada quando compartilhada por duas ou mais criaturas, e que a integridade dessa linguagem é medida pela "distância física, intelectual e espiritual" que a comunicação entre espécies é capaz de transpor (HEARNE, 2007a, p. 20) - em última análise, o que ela defende é que, na nossa interação com os animais, representamos e somos representados.

Embora a noção de representação seja estranha à discussão de Jacques Derrida sobre nossas relações com os bichos, em $O$ animal que logo sou, a defesa de que eles sejam capazes de desenvolver linguagem conduz boa parte da argumentação, que toma um viés político (não presente, por exemplo, em Hearne). Contra Aristóteles, Lacan, Descartes, Kant, Heidegger, Levinas etc., Derrida (2002, p. 62) faz questão de afirmar que o animal não é privado de linguagem, ou, mais precisamente, da habilidade de responder, de produzir uma resposta que 
se distingue rigorosamente da reação, e que envolve um direito e um poder (de responder). Com isso, o filósofo quer recuperar do domínio exclusivo do humano não a "palavra", mas a possibilidade de "aceder a um pensamento, mesmo que seja quimérico ou fabuloso, que pense de outra maneira a ausência do nome ou da palavra, e de outra maneira que uma privação" (DERRIDA, 2002, p. 89).

Derrida (2002, p. 89) sugere, assim, a tese de que pensamento animal "cabe à poesia", mas esta ainda parece presa à faceta da linguagem, e não à da experiência afetiva. O que eu quero sugerir é que, tanto quanto vislumbrar a possibilidade de compartilhar, mesmo que limitadamente, pontos de vista sobre a realidade com os animais, quando adentramos o universo poético, é igualmente fascinante nos jogarmos no espaço fora da possibilidade de linguagem. Isso não equivale, de todo, a negar a linguagem aos animais, tampouco a realçar suas diferenças em relação à nossa própria, e sim significa adentrar a dimensão do que nos falta saber, do que não se pode comunicar, daquilo que a limitação na nossa comunicação com outras espécies se traduz em algo (poeticamente) produtivo e que Coetzee define tão bem quando lança a proposta de uma imaginação cinética.

É assim que, embora os ensaios de Hearne sobre a consciência e o comportamento animal sejam interessantes, é na sua poesia que se expõe de modo mais cativante e fecundo a complexidade da relação interespécies e a perplexidade do olhar humano sobre esses "signos vivos daquilo que sempre escapa à nossa compreensão" (MACIEL, 2016, p. 13). É como se o espaço poético permitisse à autora deixar-se levar, também, para o espaço além, ou aquém, da linguagem, o que lhe possibilita penetrar espaços não circunscritos à necessidade de comunicação. Os poemas da norte-americana se deslumbram com a diversidade de modos de existência dos animais, calcados no corporal, no movimento e no pertencimento ao mundo das coisas, e o humano, ali na experiência da linguagem, busca se mover como essas criaturas. Em "Next Summer" ("No próximo verão"), por exemplo, lemos:

The body sufficient Unto itself, the body
Beautiful, and tall tales,

Hounds that race the Union Pacific,

Hearts like mountains. Hearts, but

Never to be more

Than the beloved's body

Is part of it, and the wanton hound

Should be content

With his own fleas, never mind

Ticks as big as grapefruit and what the horses

Could do. Your body sufficient

Unto me: THE HORSES?

Oh, we tagged after the horses

That was all we should have

said. ${ }^{5}$

(HEARNE, 2007b, p. 119)

Já em "Without Mountains" ("Sem montanhas"), o olhar do cão é alheio - proficuamente alheio - à interpretação da natureza: "The animal's gaze/ is impudent, love's metaphysics/ is its own in a bereft air and compensates/ for what the stars used to know. The price./ It is worth the price. It is worth it,/ for it must be worth it" 6 (HEARNE, 2007b, p. 34). O estupor da filosofia diante da natureza também aparece no poema "Road to Beauty" ("Estrada para a beleza"), no qual a beleza aparece como razão fundamental do olhar: "All things are on the road to beauty/ Or else how could we see them lurking/ in the darkness?"7 (HEARNE, 2007b, p. 36). Ago$\mathrm{ra}$, a razão humana aparece na figura do filósofo tolo e sem graça ("witless") que nega que o cão conheça, a seu modo, a nevasca. Mas, segue o poema,

[...] in their youth collie

And philosopher are both giddy

With laughter, knowing in the new fall

Of diamonds because the truth sends sparks

Flying from their paws and they worship

The way their own limbs conceive beauty

In themselves. The proper nouns betray

Philosophers long before collies

Come into them

[...]

The philosopher studies signposts 
All day, and brings home no sheep, studies Into the night, too, and the puzzling Moon remains a noun, except the mind Take up the dance, bringing the word home To stay. $[\ldots]^{8}$

\section{Consciência, presença, experiência total}

Ao pensar o jaguar de Hughes, ou os cães e cavalos dos poemas de Hearne, lembro o estado que Hans Ulrich Gumbrecht descreve como estar "perdido em intensidade focalizada" ("lost in focused intensity"), expressão emprestada ao ex-nadador Pablo Morales, que explicou sua volta às piscinas a partir do desejo de se sentir novamente imerso nessa condição, sob uma aura de intensidade que acompanha essas experiências, definidas como "estados com um grau mais alto de consciência [awareness] de nossas emoções e de nossos corpos" (GUMBRECHT, 2009, p. 150). O que Gumbrecht sugere é totalmente diferente do estado de distanciamento entre corpo e consciência que caracteriza o pensamento reflexivo, interpretativo. Pensar sobre algo é, de fato, apenas uma forma de ter algo na consciência; e o que está em jogo quando se está "perdido em intensidade focalizada" é uma outra forma de consciência, em que o corpo emerge não em contraposição ao foco da consciência, nem como o próprio foco da consciência, porém imerso na atividade que se faz esse foco.

Quando Gumbrecht escreve que, no contexto de um "perder-se em intensidade focalizada", praticar ou assistir a competições esportivas desperta um alto grau de consciência das emoções e do corpo, isso significa que a consciência está menos ocupada consigo mesma ou com outros estados cognitivos, como o juízo, o planejamento ou a interpretação, do que com conectar-se com o mundo de forma mais imediata. Essa conexão se dá a partir do aflorar à consciência das sensações, dos sentidos e da propriocepção - o conjunto de informações que, reunidas, dão as sensações de orientação espacial e movimento ao corpo - e, então, à consciência.

A proposta de Gumbrecht acerca da experiência esportiva aparece aliada a seu entendimento sobre a noção de "presença", concebida como - de forma resumida - "o impacto que objetos 'presentes' têm sobre os corpos humanos" (GUMBRECHT, 2003, p. xiv). A presença se dá sempre em um agora, em um movimento de agoras. Concentro-me, aqui, na ideia de presença como o efeito de impacto sobre nossos corpos, em detrimento da tangibilidade - porque há coisas não imediatamente tangíveis por nossas mãos que também têm potencial de "impacto imediato" sobre nossos corpos, e produzem presença. É essa ideia de presença, pensada como efeito sensorial e emocional, que introduz a imaginação como dimensão da experiência literária em que acessamos o mundo de modo não conceitual.

No exercício que este ensaio propõe, as consciências do jaguar, do cão e do cavalo seriam o "perder-se em intensidade focada" de Gumbrecht levado às últimas consequências, isto é, como se fosse possível a um humano ${ }^{9}$ desligar completamente a autoconsciência, diluindo-se em pura presença. É esse também o tipo de imaginação que evoco aqui - como terreno por definição do híbrido corpo-alma -, uma imaginação que habita e se deixa habitar sensorialmente, cineticamente, seja em momentos de suspensão do pensamento reflexivo, seja às bordas dele, e que permite que se disparem todos os tipos de afetos.

Se "o mundo rola embaixo do ímpeto" das patas do jaguar, ele rola também sob os pés do leitor. Se, "no chão de sua jaula se derramam os horizontes", são também esses horizontes que se derramam na leitura, com as possibilidades de sermos e nos vermos, experimentando o que somos para além da atualidade, isto é, na potencialidade: levando nossa capacidade de performar, imaginariamente, o texto para um domínio não restrito por uma só forma de consciência, operada estritamente pela razão tal como a concebemos.

Evocar um modo de refletir sobre a literatura com base no terreno do pós-humano, isto é, a partir da consciência animal ou mesmo das elucubrações da ficção científica sobre consciências extraterrestres, é promissor para que se repense o próprio conceito de representação, a partir da problematização da razão como "primeiro princípio do universo", para voltar a Elizabeth Costello. E nem é preciso irmos tão longe: morcegos, jaguares, cães, cavalos. Como Coetzee (1999, p. 23), pela voz de Costello, nos adverte, é bastante suspeito que a razão - esta que, "para Platão, para Tomás 
de Aquino, para Descartes, cada um a seu modo", é "o ser de Deus", sobre o qual se construiu o universo - seja, coincidentemente, "a essência do pensamento humano", ou, mais estreitamente, a tradição filosófica ocidental.

\section{Ampliação do mundo}

A investigação poética sobre a consciência animal e sobre o estar afetivamente no mundo, que guiou as últimas páginas, gira em torno de, ou alimenta a reflexão sobre a experiência consciente de leitura. Como pensá-la em uma proposta para que se alarguem as possibilidades de pensar os modos de viver a literatura? É da tensão entre os estados de consciência, estados reflexivos, emotivos e sensoriais, alguns simplesmente instantaneidades somáticas, que surge a força da experiência da arte. Com isso, não se defende aqui a primazia de um ou de outro - afeto ou sentido, corpo ou alma -, mas justamente a potência produzida por sua mútua resistência, resistência não rija, mas elástica. Do conflito, no entanto, todos sabemos quem costuma sair vencedor. $\mathrm{O}$ que define o ser humano, e este é o trunfo inabalável de Descartes, é a autoconsciência, da qual só escapamos muito marginal ou brevemente ou pela via não desejável do alienamento mental. "The Soul condemned to be -/ Attended by a single Hound/ Its own identity", já havia escrito Emily Dickinson (1976, p. 399, n. 822).

Para além da assustadora solidão da autoconsciência, um melancólico paradoxo - latente neste ensaio - é que só atribuímos importância aos afetos por sua análise reflexiva. Uma experiência viva, ou mesmo um instante de presença, só existe para nós de modo a podermos compartilhá-la ou acioná-la voluntariamente, quando circunscrita em experiência pensada. Para levar a questão a um extremo, além da experiência animal, seria perfeitamente possível, como escreve Charles Peirce (1974, p. 153, CP I.310), concebermos um ser cuja consciência inteira seja feita apenas de cor, ao longo de um período temporal, e assim em todo instante desse período. "Mas esse ser nunca saberia nada sobre sua própria consciência. Nunca pensaria nada que pudesse ser expresso em uma proposição. [...] Ficaria sempre confinado a sentir aquela cor."
Nesse sentido, uma defesa da liberdade da imaginação e seus afetos na leitura literária pode ter como consequência uma leitura reflexiva que resista a ela. $\mathrm{O}$ que eu proponho aqui é uma não resistência, isto é, uma comunhão, uma soma que é maior do que suas partes. Com essa ideia em mente, penso que nos deslocarmos do espaço convencional no pensamento ocidental, em que a razão subjuga quase sempre outras possibilidades conscientes, poderemos pensar um conceito de representação mais amplo, que dê conta também de potencialidades nossas e do mundo.

Se entendermos a experiência literária como um modo de constituir conhecimento - e se recusarmos a ideia de que todo conhecimento deve ser reconhecido, pela autoconsciência, como conhecimento de algo alheio a nós, enquanto sujeitos -, pensemos a literatura como um alargamento de espaço, como uma ampliação do mundo-coisa de que somos parte, como uma volta à casa que, ao mesmo tempo que estende nosso entendimento racional sobre o mundo, nos redime ao nos reconectar fugazmente, como corpos que também somos, a ele. O exercício imaginativo de alteridade radical que é pensar o modo não humano de estar no mundo, isto é, de nos colocarmos sob a pele dos animas, parece-me um ponto de partida válido para essa ampliação de mundo oferecida pela experiência literária. Adentraríamos, assim, o mundo ficcional e poético não só como os seres interpretativos que somos, mas também da forma como (imaginamos que) os cães correm pelos quintais em busca de sol, à caça de esquilos ou calangos, no deleite dos próprios movimentos e sensações. Recusando - paradoxalmente, com os olhos postos sobre as páginas cobertas de letras - a linguagem como único paradigma do compartilhamento de espaços, é possível conceber uma outra forma de pensamento, isto é, de estar no mundo, como o que o poeta contemporâneo norte-americano Matthew Rohrer (2009, p. 25) sugere em um poema simples, mas exato:

Some guy says Wittgenstein proved there's no thought without language.

Wittgenstein had never seen a bird or a bear.

Trees swayed in the park and their tops touched tenderly.

Even though I'm the youngest, I am the teacher! 
On the roof the crows caw at me, and can't land. I wake indistinguishable from the washed-out morning.

All I am is thought without language. ${ }^{10}$

\section{Notas}

1. Ver <http://english.lem.pl/arround-lem/adaptations/ qsolarisq-by-tarkovsky>

2. Tradução minha a partir da versão em inglês. Neste artigo, todas as traduções de originais no inglês são de minha autoria.

3. "[T]here is something it is like to be that organism."

4. Na tradução de Sérgio Alcides: "Macacos se espreguiçam cultuando pulgas ao sol./ Guincham os papagaios, como ardendo, ou gingam/ Feito putas a fim de atenção e amendoim./ Fatigados pela indolência, o tigre e o leão/ Jazem imóveis como o sol. $\mathrm{O}$ rolo da jiboia/ Fossiliza-se. Jaula após jaula está vazia, ou/ Fede ao palheiro onde tresanda um dorminhoco./ Para pintar num quarto de criança a cena é boa./ Mas quem percorre a ala com os outros atinge/ A jaula onde uma multidão vem ver, mesmerizada/ Como criança sonhando, um jaguar furioso a girar/ Pelo breu da prisão que a broca do seu olhar punge/ Num curto pavio feroz. Sem fastio -/ Os olhos contentes no seu fogo cegante,/ Os ouvidos ao surdo tambor do seu sangue - / Revolta-se ante as grades, mas para ele não há jaula/ Mais do que para o visionário existe sua cela:/ É seu passo o sertão que a liberdade tem defronte:/ O mundo rola embaixo do ímpeto de suas patas./ No chão de sua jaula se derramam os horizontes" (HUGHES, 2010b, p. 40).

5. "O corpo suficiente/ rumo a si mesmo, o corpo/ Belo, e como histórias inverossímeis/ Cães que correm milhares de quilômetros de ferrovias/ Corações como montanhas. Corações, mas/ Nunca ser mais/ Do que o corpo do amado/ É parte disso, e o cão travesso/ Deve estar contente/ Com suas próprias pulgas, e não se importar/ Com carrapatos enormes como toranjas e com o que os cavalos/ Poderiam fazer. Teu corpo suficiente/ Rumo a mim: OS CAVALOS?/ Ah, nós seguimos de perto os cavalos/ Era isso tudo o que deveríamos ter/ Dito."

6. “O olhar do animal/ é atrevido, a metafísica do amor/ é toda sua de um modo despojado e compensa/ o que as estrelas costumavam saber. O preço./ Ele vale o preço. Vale, / pois precisa valer."

7. "Todas as coisas estão a caminho da beleza/ Por que mais as veríamos à espreita/ na escuridão?".

8. “[...] quando jovens, tanto o collie/ Quanto o filósofo exultam,/ Em gargalhadas, sabendo da próxima chuva/
De diamantes, porque a verdade envia faíscas/ A voar de suas patas, e eles veneram/ O modo como seus próprios membros concebem beleza/ Em si mesmos. Os nomes próprios traem/ Os filósofos muito antes de os collies/ Depararem com eles/ [...] O filósofo estuda sinalizações/ Todo o dia, e não traz para casa nenhum rebanho, estuda/ Também durante a noite, e a lua/ incompreensível permanece um nome, ainda que a mente/ aceite a dança, trazendo a palavra de volta à casa/ para lá ficar $[\ldots]$ ".

9. E faço a ressalva de que sequer sabemos se isso é possível a um jaguar, um cavalo ou um cão.

10. Na tradução de Sylvio Fraga Neto: "Algum cara disse que Wittgenstein provou que não há pensamento sem linguagem./ Wittgenstein nunca viu um passarinho ou um urso./ Árvores balançavam no parque e suas copas se encostavam com ternura./ Mesmo sendo o mais novo, eu sou o professor!/ Corvos gritam para mim no telhado e não conseguem pousar./ Acordo indistinguível da manhã deslavada./ Tudo que sou é pensamento sem linguagem" (WOODWARD; ROHRER; ZAPRUDER, 2013, p. 65).

\section{Referências}

ABEL, Marco. Violent Affect: literature, cinema, and critique after representation. Lincoln, London: University of Nebraska Press, 2007.

COETZEE, J. M. The Lives of Animals. Princeton: Princeton University Press, 1999.

DERRIDA, Jacques. O animal que logo sou. Tradução Fábio Landa. São Paulo: Editora Unesp, 2002.

DICKINSON, Emily. The Complete Poems. Boston, New York: Back Bay, 1976.

GUMBRECHT, Hans Ulrich. Production of Presence: What Meaning Cannot Convey. Stanford: Stanford University Press, 2003.

“'Lost in Focused Intensity': Spectator Sports and Strategies of Re-Enchantment". In: LANDY, JOSHUA; SALER, MICHAEL (Org.). The Re-Enchantment of the World: Secular Magic in a Rational Age. Stanford: Stanford University Press, 2009. p. 149-158.

HEARNE, Vicki. Adam's Task: calling animals by name. New York: Skyhorse, 2007a.

Tricks of the Light: new and selected poems. Chicago: University of Chicago Press, 2007b.

HEIDEGGER, Martin. The Fundamental Concepts of Metaphysics: World, Finitude, Solitude. Tradução William McNeill; Nicholas Walker. Bloomington, Indianapolis: Indiana University Press, 1995. 
. "The Origin of the Work of Art". Poetry, Language, Thought. Tradução Albert Hofstadter. New York: Harper \& Row, 2013. p. 15-86.

HUGHES, Ted. New Selected Poems 1957-1994. London: Faber and Faber, 2010a.

O jaguar. Suplemento Literário, n. 1332, p. 40, 2010b. Tradução Sérgio Alcides. Acesso em: 2 set. 2015.

LEM, Stanislaw. Solaris. Tradução Joanna Kilmartin; Steven Cox. New York: Faber and Faber, 1970.

LÉVI-STRAUSS. Leçon décriture. Tristes tropiques. Paris: Plon, 1955. p. 347-360.

LIBRANDI-ROCHA, Marília. Escutar a escrita: por uma teoria literária ameríndia. O Eixo e a Roda, v. 21, n. 2, p. 179-202, 2012.

MACIEL, Maria Esther. Literatura e animalidade. Rio de Janeiro: Civilização Brasileira, 2016.

NAGEL, Thomas." What is it like to be a bat?" The Philosophical Review, v. 83, n. 4, p. 435-450, 1974.

PEIRCE, Charles Sanders. Collected Papers. Cambridge, MA: Harvard University Press, 1974. v. I - Principles of Philosophy.

ROHRER, Matthew. A Plate of Chicken. Brooklyn: Ugly Duckling, 2009.

SMITH, Mick. "Road Kill: remembering what is left in our encounters with other animals". In: SMITH, MICK et al. (Org.). Emotion, Place and Culture. Farnham, Burlington: Ashgate, 2009. p. 21-34.

TARKOVSKIAEI, Andreaei Arsensevich. Esculpir o tempo. Tradução Jefferson Luiz Camargo. São Paulo: Martins Fontes, 1998.

WOODWARD, Jon; ROHRER, Matthew; ZAPRUDER, Matthew. $O$ andar ao lado: três novos poetas norteamericanos. Tradução Sylvio Fraga Neto. Rio de Janeiro: 7Letras, 2013. 